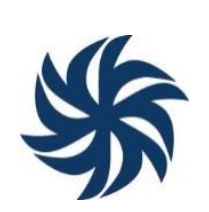

\title{
REPRESENTAÇÃO POLÍTICA DA BAHIA NA CÂMARA DOS DEPUTADOS: AS ELITES DO PODER DURANTE O REGIME MILITAR
}

\author{
POLITICAL REPRESENTATION OF BAHIA IN THE HOUSE OF \\ REPRESENTATIVES: THE POWER ELITES DURING THE MILITARY REGIME
}

\author{
REPRESENTACIÓN POLÍTICA DE BAHÍA EN LA CÁMARA DE DIPUTADOS: LAS \\ ÉLITES DEL PODER DURANTE EL RÉGIMEN MILITAR
}

\author{
Maurício Ferreira Silva ${ }^{1}$ \\ Ana Quele Passos ${ }^{2}$
}

\begin{abstract}
Resumo: O presente trabalho aborda a representação política do estado da Bahia na Câmara dos Deputados durante o regime militar. O objetivo é identificar, a partir da análise sociopolítica, os segmentos sociais majoritários que se destacaram na casa legislativa em quatro categorias analíticas: sexo, nível educacional, carreira profissional e vinculação partidária. O percurso metodológico traçado teve como ponto de partida a análise documental, coleta e sistematização de dados biográficos, seguindo abordagem qualitativa e quantitativa de caráter descritivo. O trabalho traz como resultado a construção de uma radiografia política que, por sua vez, apresenta duas importantes conclusões acerca do perfil representativo: o viés elitista, em função da identificação com os grupos de privilégio da sociedade e o atrelamento ideológico aos governos militares.
\end{abstract}

Palavras-chaves: Representação política; Câmara dos Deputados; Regime militar; Elites baianas.

\begin{abstract}
This paper deals with the political representation of the state of Bahia in the House of Representatives during the military regime. The objective is to identify, from the socio-political analysis, the major social segments that stood out in the legislative house in four analytical categories: gender, educational level, professional career and party affiliation. The methodological course was based on document analysis, collection and systematization of biographical data, following a qualitative and quantitative descriptive approach. The work results in the construction of a political radiography that, in turn, presents two important conclusions about the representative profile: the elitist bias, due to the identification with the privilege groups of society and the ideological attachment to the military governments.
\end{abstract}

Keywords: Political representation; House of Representatives; Military Regime; Elites of Bahia.

Resumen: Este documento aborda la representación política del estado de Bahía en la Cámara de Diputados durante el régimen militar. El objetivo es identificar, a partir del análisis sociopolítico, los principales segmentos sociales que se destacaron en la casa legislativa en cuatro categorías analíticas: género, nivel educativo, carrera profesional y afiliación partidaria. El curso metodológico se basó en el análisis de documentos, la recopilación y la sistematización de datos biográficos, siguiendo un enfoque descriptivo cualitativo y cuantitativo. El trabajo resulta en la construcción de una radiografía política que, a su vez, presenta dos conclusiones importantes sobre el perfil representativo: el sesgo elitista, debido a la identificación con los grupos privilegiados de la sociedad y el apego ideológico a los gobiernos militares.

Palabras clave: Representación política; Cámara de los Diputados; Régimen militar; Élites bahianas.

\footnotetext{
${ }^{1}$ Cientista Político. Docente Associado do Centro de Artes, Humanidades e Letras (CAHL) da Universidade Federal do Recôncavo da Bahia (UFRB). Atua em cursos de graduação e nos Programas de Pós-Graduação em Política Social e Territórios (POSTERR) Ciências Sociais (PPGCS).

2 Mestranda em Ciências Sociais pelo PPGCS-UFRB. Membro do Grupo de Estudo e Pesquisa em Política e Sociedade (GEPPS-UFRB).
} 


\section{Introdução}

A onda de golpes vivenciados por Estados independentes a partir da década de 1960 na América do Sul consolidou os interesses das elites conservadoras que, baseadas no autoritarismo e na repressão política, expandiram-se por toda a região. Os golpes de Estado pelos quais passaram Brasil (1964), Bolívia (1964), Argentina (1966; 1976), Chile (1973) e Uruguai (1973), reverberaram um misto de interesses das elites nacionais em conjunto com as pretensões das forças armadas, interligados aos anseios das forças políticas transnacionais. No caso brasileiro, a ditadura civil-militar contou com o apoio de políticos reconhecidos nacionalmente, sobretudo vinculados à ARENA (Aliança Renovadora Nacional), partido que representou os interesses políticos dos militares no sistema bipartidário imposto após o golpe.

No processo de fortalecimento do regime, esta coalização conservadora, representada principalmente por seguimentos militares, industriais, financeiros e rurais, foi responsável pela participação ativa em cargos públicos de representação política, tanto em nível regional quanto nacional. No caso da Bahia, como aponta Dantas Neto (2004), o golpe reorientou a linha político- administrativa do governo estadual, cassou mandatos, recuperou a influência nacional de Juracy Magalhães e converteu Luís Viana Filho e Antônio Carlos Magalhães em influentes quadros políticos do regime. Sob um cenário político de exceção, o projeto de desenvolvimento econômico centrou-se, a partir do destacado papel da elite política local, nos preceitos da chamada "modernização conservadora".

Este trabalho tem como objetivo principal analisar o perfil elitista da representação baiana na Câmara dos Deputados durante o regime militar. Em termos específicos se divide em três etapas: a primeira condiz com a identificação dos parlamentares eleitos para a representação da Bahia na Câmara Federal durante o regime militar (1967-1982); a segunda se refere à identificação, a partir de levantamento do perfil biográfico dos representantes, da vinculação aos grupos de influência nas quatro categorias analíticas selecionadas - gênero, nível educacional, carreira profissional e filiação partidária; a última averigua o alinhamento político do grupo de representantes com o regime militar.

A pesquisa, de caráter descritivo, seguiu abordagem qualitativa e quantitativa, tendo como ponto de partida o mapeamento do perfil biográfico dos deputados federais da Bahia que exerceram mandatos, o que inclui eventuais suplentes alçados à condição de titulares. Além disso, o percurso metodológico traçado teve como ponto de partida a análise documental, coleta e sistematização de dados biográficos através de fontes secundárias, tais como o banco de dados do Centro de Documentação e Informação (CEDI), o Dicionário HistóricoBibliográfico Brasileiro (DHBB) do Centro de Pesquisa e Documentação de História Contemporânea do Brasil (CPDOC/FGV) e dados disponíveis nos sites da Câmara dos Deputados e do Tribunal Superior Eleitoral. 
$\mathrm{O}$ artigo está estruturado em duas partes principais. A primeira se destina ao debate em torno dos campos teóricos das elites políticas e da representação política à luz do quadro sociopolítico do regime militar. A segunda, por sua vez, apresenta os resultados da coleta de dados em torno das quatro variáveis vinculadas ao perfil da representação parlamentar.

\section{Elites e representação política}

O debate teórico e metodológico no campo da teoria das elites perpassa pelo reconhecimento de um grupo de comando, dirigente e governante, que por sua vez ocupa posições estratégicas numa dada relação de poder. Estes princípios são evidenciados por fatores de distinção que caracterizam a elite e a "não-elite". Nesta ótica, num contexto social específico, é intrínseca a existência de uma massa (maioria da população) que não é habilitada a governar, uma vez que não possui condições necessárias para ocupar determinados espaços de poder e mando.

Os teóricos clássicos introduziram a discussão sobre as elites como princípio analítico e explicativo da organização social, política e cultural, que considerava a presença eminente de hierarquias e desigualdades "naturais" entre os membros da sociedade. Tal posição evidencia que a visão elitista objetivou a compreensão da organização política na práxis, interrelacionada com a análise e crítica da concepção de democracia que supostamente se distanciava de seus preceitos ideais. Logo, no que tange à organização sociopolítica, este pressuposto justifica a necessidade de uma minoria dirigente, capaz de governar a maioria da população.

O sentido sociológico da noção de elites ganha ressonância com o trabalho de Pareto (1984), que lhe confere duas diferentes definições. A elite comporia o estrato superior de uma sociedade, responsável pela organização, controle e direção do estrato inferior, definido como "não-elite". O estrato superior comportaria duas elites, a dos governantes e a dos nãogovernantes.

Em linhas gerais, o que define a composição e o estabelecimento nos grupos em questão são as aptidões individuais, logo, segundo tal concepção, o grupo dirigente possui os atributos necessários para a ação de controle. Não se trata, pois, de fenômeno isolado e circunstancial, visto que, segundo Gaetano Mosca, a separação entre grupos dirigentes e grupos dirigidos é um fenômeno histórico, aplicado às mais distintas formas de organização social. Isso torna impossível, por exemplo, "que uma democracia funcione sem que a ação das massas populares seja coordenada e disciplinada por uma minoria organizada, ou seja, também por uma classe dirigente" (MOSCA, 1968, p. 307).

O poder dirigente da minoria se manifesta, sobretudo, pela ausência de condições de autocontrole da maioria. Pareto e Mosca defendem a noção de que toda sociedade necessita de 
uma minoria governante - uma elite governante - dotada de qualidades políticas para o exercício do poder. Esta elite, por sua vez, não é estática, já que sofre transformações em sua composição de tempos em tempos, seja pela própria dinâmica interna ou pelo recrutamento de novos membros advindos dos estratos inferiores da sociedade. Por este prisma, os preceitos clássicos de rotatividade dirigente da democracia, sobretudo o sufrágio universal, constituem risco ao equilíbrio.

No entanto, na luta política, a fim de obter os sufrágios da maioria, cada grupo se esforça por conformar-se, ao menos em aparência, às ideias e aos sentimentos que predominam nessa mesma maioria. Isto permite muitas vezes aos regimes liberais desenvolver uma força extraordinária, mas, por outro lado, esta obrigação de conformismo faz com que a classe dirigente sofra a influência de elementos mais numerosos, que são menos conscientes das necessidades verdadeiras da sociedade. Esta é a razão por que o maior perigo que correm as instituições liberais consiste nas consequências do exercício do direito de sufrágio pelas camadas mais incultas da população. (Idem, p. 313-314)

Ao considerar as associações como meios constitutivos da vontade geral, Robert Michels prescreveu a lei de ferro das oligarquias que se movia pela necessidade de organização que implica, por sua vez, na existência de uma minoria dirigente. Entre estas vias, Michels (1982) observa que a crescente burocratização recorre a um distanciamento com a vontade das massas governadas, logo, a democracia representativa em sua práxis coaduna requisitos ora prescritos pelos teóricos elitistas. Com base nas análises sobre a composição da representação política, indica que este quadro foi composto historicamente por personas que em grande escala pertenciam aos grupos de elites correspondentes entre si.

Em vista de tal argumentação, Josep Schumpeter retoma o princípio das elites dirigentes como característica da democracia real. Tendo por base o preceito de utilidade, Schumpeter (1984) traduz a existência das elites como pressuposto necessário para a condução da própria democracia. Por conseguinte, sua crítica perpassa ao idealismo prescrito no sentido original do termo, pelo qual o povo é tido como condutor da vontade e práxis democrática.

\begin{abstract}
A sociedade é sempre uma unidade dinâmica de dois fatores: minorias e massas. As minorias são indivíduos ou grupos de indivíduos especialmente qualificados. A massa é o conjunto de pessoas não especialmente qualificadas [...] Claro está que nas superiores, quando chegam a sê-lo e enquanto o forem de verdade, há mais verossimilitude de achar homens que adoram o "grande veículo", enquanto as inferiores estão normalmente constituídas por indivíduos sem qualidade. (ORTEGA Y GASSET, 1959, p. $58-60)$.
\end{abstract}

Neste sentido, a participação direta e o autogoverno do povo se tornam impossíveis, uma vez que os indivíduos tendem para práticas ora distanciadas da razão e produzem diferentes percepções que se chocam com o consenso previsto na teoria clássica da democracia. Em função de tais contradições, o teor de democracia em uma esfera política se concretiza na 
competição entre as elites e os conflitos pelo poder são guiados pelo que designou como "autointeresse".

As premissas elitistas em torno da representação política sustentam-se em cenário de competição restrita, ou seja, estabelecida a partir de regras de controle do funcionamento da democracia representativa. Contudo, é importante ressaltar que a ascensão de elites na representação política não se resume a contextos de competição limitada. Como aponta Dahl (2005) acerca da contemporaneidade, é possível verificar a proeminência de deturpações na constituição de parlamentos em contexto de democracia políárquica, que resulta na inexistência de simetria entre a representação com as camadas sociais representadas.

Nos corpos legislativos contemporâneos, as ocupações profissionais e de classe média estão numericamente sobre-representadas; As ocupações em trabalho fabris estão sub-representadas (mesmo entre representantes de partidos trabalhistas, socialistas e comunistas, assim como muitas outras categorias- agricultores e donas-de-casa, por exemplo). (DAHL, 2005, p.43).

\subsection{A representação no regime de exceção}

O movimento de substituição de regimes democráticos por ditatoriais, verificado na América Latina a partir da década de 1950, ocorreu através de golpes de Estado capitaneados por segmentos elitistas de interesses nacionais e internacionais com o uso das forças armadas. Os regimes militares resultantes predominaram na região durante duas décadas, sendo que "somente no final dos anos 1970 e 1980 é que os militares se retiraram de maneira significativa do controle direto do governo em toda a região" (HARTLYN, 2009, p. 128).

No Brasil, após o golpe de 1964, os militares impuseram um modelo de governo que tentava convergir preceitos democráticos às ações ditatoriais. Do ponto de vista ideológico, o regime se empenhou em legitimar o discurso da necessidade da "revolução" como mecanismo de combate ao "perigo comunista" que ameaçava a democracia. Concomitantemente, no sentido da dinâmica política estrutural, amparou-se na ambiguidade de ações autoritárias - como o fechamento do Congresso Nacional - e a manutenção de uma versão de competição eleitoral, com eleições legislativas e a existência de partidos políticos. Com isso, o Ato Institucional número 2 (AI2) impôs o mecanismo de dois partidos para as disputas eleitorais, o chamado bipartidarismo.

Em sentido amplo pode-se afirmar, contudo, que a "roupagem democrática" não retirou o viés elitista e autoritário do governo, pelo contrário. O golpe foi executado pelas forças militares em conluio com setores da sociedade civil agregando "um conjunto heterogêneo de novos e velhos conspiradores contra Jango e contra o trabalhismo: civis e militares, liberais e autoritários, empresários e políticos, classe média e burguesia”. (NAPOLITANO, 2014, 43-44).

Se em cenários de ampla concorrência as variáveis de privilégios das elites podem ser 
garantidas, como aponta Dahl (2005), é possível aferir que, no caso do regime militar brasileiro, o mecanismo bicameral e de restrições ao sufrágio universal possibilitou maior controle dos militares sobre as instâncias representativas que vigoravam antes do golpe de 1964. A restrição competitiva, como se constata em torno da representação política no estado da Bahia, proporcionou a eleição de atores políticos oriundos das camadas privilegiadas da sociedade que se posicionavam, em termos ideológicos, alinhados com os interesses políticos da elite dirigente.

\section{Resultados}

Os estudos em torno da representação política brasileira evidenciam que, historicamente, algumas elites se destacaram nas casas legislativas, o que proporcionou significativa ausência representativa de segmentos sociais, tais como mulheres, negros e indígenas. Somam-se a estes os grupos de menor poder aquisitivo e de baixa formação escolar. Em contrapartida, como veremos nesta seção a partir do recorte em torno do período que compreende o regime militar, existe a predominância de segmentos privilegiados compostos por homens com formação superior em áreas de prestígio social.

\subsection{A supremacia masculina}

A bancada baiana na Câmara dos Deputados foi representada majoritariamente por parlamentares do sexo masculino, como demonstra o Gráfico 1.

Gráfico 1: Parlamentares baianos por gênero (1967-1982)

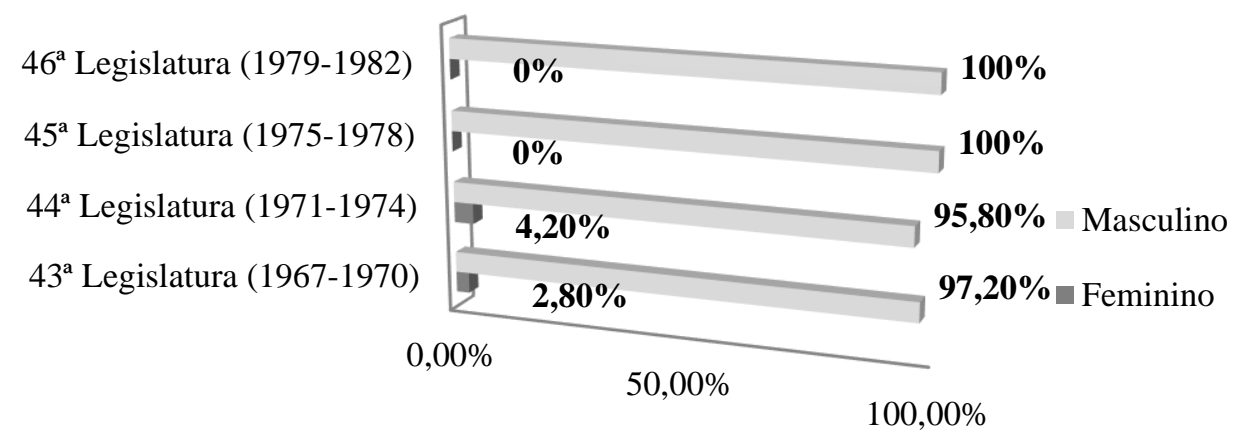

Fonte: Dados Organizados pelos autores. 
$\mathrm{Na} 43^{\text {a }}$ Legislatura (1967-1970) a representação englobou 97,2\% de homens contra apenas 2,8\% de representação feminina. Na legislatura seguinte $\left(44^{\mathrm{a}}\right)$ o placar percentual evidencia $95,8 \%$ de representação masculina ante $4,2 \%$ de feminina. Se o índice de representação feminina é baixo nas duas primeiras legislaturas, adquire contornos medíocres nas legislaturas seguintes, onde se nota a ausência total de representação feminina. Isso significa que nenhuma mulher participou da representação política do estado da Bahia entre os anos de 1975 e 1982. Assim, por consequência, pode-se aferir um viés mais elitista na segunda metade do regime militar, com hegemonia masculina na representação política baiana.

Não obstante verifica-se que, no quadro geral, apenas $1,4 \%$ desta representação foi exercida por mulheres parlamentares. Neste caso, destaca-se que a eleição da única mulher se encontra entrelaçada ao contraste de um contexto histórico marcado pela sub-representação feminina e, por outro lado, pelo arranjo protagonizado por lideranças políticas na transmissão de capital político para correligionários e familiares. A professora Neci Novais, esposa de Manuel Cavalvanti Novais, membro da elite baiana com forte inserção no cenário político do estado que remonta ao início da década de 1930, protagonizou a condição de única mulher eleita à Câmara dos Deputados pela Bahia no período pesquisado. Junto com Manuel Novais exerceu mandato na 42 $2^{\mathrm{a}}$ legislatura (1963-1967) vinculada ao Partido Trabalhista Brasileiro - PTB e, após a

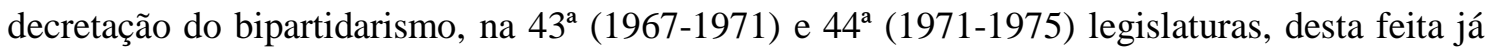
vinculada à ARENA.

A constatação de que, em termos absolutos, apenas uma mulher assumiu mandato durante o período, expõe o viés elitista centrado na figura masculina como "controlador" do campo político no estado. Cabe salientar que esta realidade encontra ressonância no cenário nacional, visto que o regime militar se caracterizou pela supremacia masculina nos postos de comando das forças armadas e, por consequência, nos cargos administrativos dos governos subnacionais e nacional.

\subsection{Uma elite de formação superior}

A política brasileira foi marcada historicamente pela presença de atores e representantes que dispõem de alto nível educacional (RODRIGUES, 2009). Ao analisar os bacharéis na política brasileira, Simões (2006) aponta que esses, principalmente da área do direito, desempenharam grande atuação no campo político e tinham por característica a questão do treinamento através da formação educacional.

A formação escolar elevada dos representantes é característica marcante do quadro de representação política nacional. Considerando o período aqui pesquisado pode-se concluir que a maior parcela da população foi alijada da atividade representativa, já que a taxa de participação do ensino superior no total de matrículas iniciais representou apenas 2\% até a década de 1970 
(PNUD/IPEA, 1996). Essa condição excludente e de elitização da representação permanece durante a década de 1980, visto que o índice de pessoas aptas que frequentaram o nível superior não ultrapassou 6\% (FIGUEIREDO FILHO, 2010).

Em termos regionais constata-se que o estado da Bahia foi marcado por alta taxa de analfabetismo durante a década de 1960. Esta realidade motivou os estudantes reunidos no I Seminário Nacional de Reforma Universitária de 1961, organizado pela União Nacional dos Estudantes (UNE), a denunciar o sistema educacional, pois "apenas 1\% da população baiana tinha acesso ao ensino superior". (SOUZA, OLIVEIRA e MAGALHÃES, 2015). Em 1990 o número médio de anos de estudos da população baiana foi menor que 04 (quatro), o que alocou o estado na sexta menor expectativa de desenvolvimento educacional. (PNUD/IPEA, 1996).

Diferente da maioria da população baiana da época, os deputados federais do estado apresentaram um alto nível de graduação educacional ratificado pelo título de ensino superior, o que os distingue socialmente. Os dados abaixo constituem, no nosso entendimento, mais uma evidência do alto nível de elitização da representação política baiana durante o período.

Gráfico 2: Parlamentares baianos por nível de graduação educacional

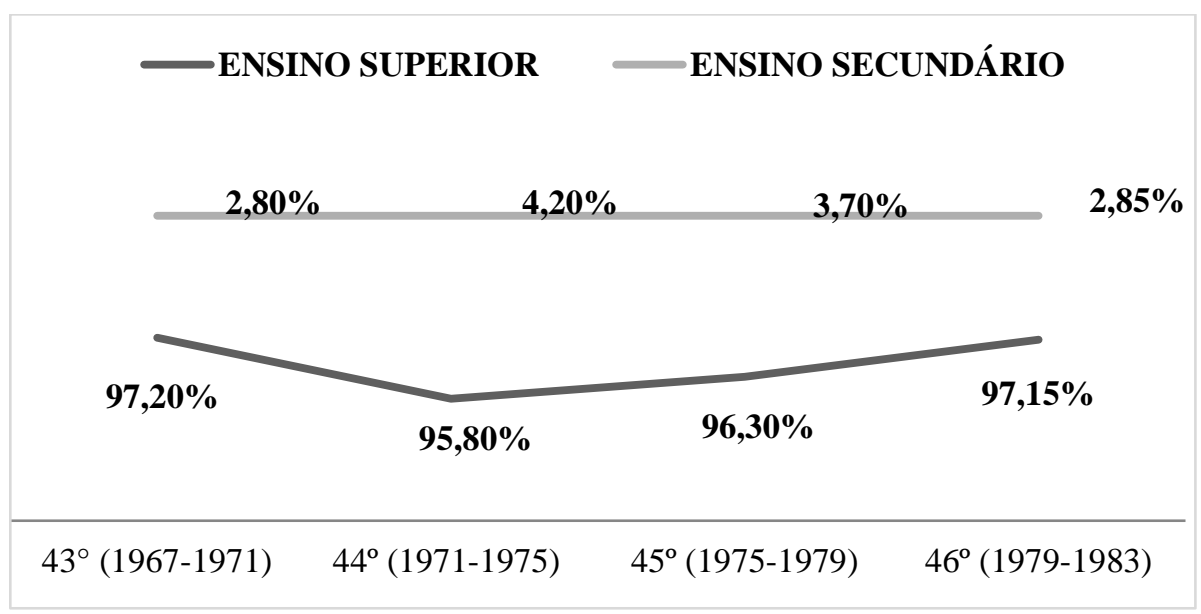

Fonte: Dados organizados pelos autores.

O nível de graduação educacional dos deputados federais da Bahia está em congruência com o perfil apresentado na esfera nacional, o que retrata para a formação característica dos grupos de elites da época. Segundo os dados da $43^{\circ}$ legislatura, 97,2\% dos representantes eleitos portaram nível superior, maior índice evidenciado no período analisado; por outro lado, os que detinham o nível de graduação secundária somaram apenas $2,8 \%$ do número total. 
As legislaturas posteriores coadunam-se com a mesma média de formação superior, com índice acima de 90\%. Já os portadores do ensino secundário representam menos de 5\% dentre os 70 parlamentares que cumpriram 120 mandatos como representantes da bancada baiana na Câmara dos Deputados durante o regime militar. Isso, como afirmamos, expõe a face excludente do processo de representação nas quatro legislaturas pesquisadas.

\title{
3.3 Carreira profissional: o prestígio social em voga
}

A literatura sobre o processo de recrutamento político, a composição das instâncias político-institucionais e o estudo sobre as elites políticas incorporam a categoria "carreira profissional" como um importante indicador analítico da classe política e sua profissionalização. Tal categorização, para além de descrever e traçar informações, também pode evidenciar aspectos de influência para o processo de recrutamento político da época. De acordo com Norris (2013), o recrutamento político perpassa a mera indicação da representação e configura a seleção de atores específicos, tendo em vista o arranjo de posições estratégicas nas esferas políticas.

Desta forma, as ocupações profissionais, principalmente as que dispõem de maior entendimento técnico das leis, podem contribuir para o acesso ao parlamento, como as profissões que advêm da área jurídica ou que possuem um determinado prestígio social, a exemplo dos profissionais liberais como médicos, engenheiros e empresários. Segundo Codato, Costa e Massimo (2014), a posição de uma determinada profissão tem potencial para fornecer critérios de convergência com o recrutamento e com a profissionalização da atividade política:

\begin{abstract}
Os três critérios ligados à profissão do aspirante a político, e que, combinados, mediriam as oportunidades oferecidas pelo sistema de relações sociais, são: a) carreira flexível (férias generosas, disponibilidade de tempo e autonomia profissional); b) status social (posição da ocupação perante outras de acordo com o reconhecimento e o prestígio socialmente compartilhado numa dada comunidade 12); e c) afinidade com a atividade política (ocupações que permitem familiaridade com a máquina pública e com os estratagemas da política ou propiciam uma rede de contatos importantes no meio). Decorrem daí três categorias de ocupações que reúnem, de maneira diferente, os requisitos estipulados para se dar bem no negócio da política: profissões com alta disposição para a atividade política, com média disposição para a atividade política ou com baixa disposição para a atividade política (CODATO, COSTA E MASSIMO, 2014, p.355).
\end{abstract}

Mesmo ao considerar as especificidades do período pesquisado, sobretudo, ao que concerne às limitações do sufrágio para o legislativo, pode-se aferir que o perfil da representação coaduna-se aos preceitos de diferenciação e consequente privilégio em termos de profissões. De acordo com Simões (2006), entre os advogados, legisladores, juízes, professores em direito, escritores de obras jurídicas e procuradores, observa-se a existência de características comuns que os diferenciam socialmente, atribuindo-lhes status e alto 
reconhecimento social:

O que tem em comum advogados, legisladores, juízes, professores de direito, escritores de obra jurídicas e procuradores? Primeiro: têm um referencial comum de linguagem, o que chamou-se de língua estranha ao leigo e de formação; segundo: são reconhecidos como tendo este tipo específico de conhecimento; e, por fim: são aceitos como pares um pelos outros. Em suma, fazem parte de um coterie. (Grupo de pessoas que se prestam apoio mútuo) (SIMÕES, 2006, p.38)

Mediante tais descrições, os grupos de profissionais organizam-se como membros de uma coterie (grupo de pessoas que se prestam ao apoio mútuo), que contribui de forma partilhada para o reconhecimento e prestigio social. Neste sentido, a hipótese que hora norteia esta categoria de análise infere que a representação política da Bahia na Câmara dos Deputados nas legislaturas pesquisadas foi constituída de políticos pertencentes a profissões de reconhecimento social.

Convém ressaltar que, de acordo com as informações cedidas e catalogadas pelo Centro de documentação e Informação da Câmara dos Deputados, alguns deputados declararam mais de uma profissão. Assim, foram analisadas as ocupações profissionais dos 70 parlamentares baianos eleitos entre 1967 a 1979, entre suplentes e efetivos, que elencaram 143 ocupações profissionais. Além disso, nota-se a ocorrência de dubiedade entre as profissões declaradas e as profissões exercidas, uma vez que os arquivos não diferenciam entre a formação original e o pleno exercício profissional. Neste sentido, ocorrem situações nas quais o parlamentar obteve determinada formação acadêmica, migrou para outra atividade e registrou todo o percurso como "profissão", como foi o caso do deputado Antônio Carlos Magalhães que, em seu perfil, inseriu as profissões "médico e jornalista" sem jamais ter exercido atividade profissional na medicina, apesar da formação acadêmica neste campo.

A multiplicidade das declarações indica, contudo, a aderência às profissões de maiores distinção e reconhecimento social. Independentemente dos partidos políticos, essas profissões são características dos grupos de elite da sociedade baiana, o que denota o importante papel que exercem para o acesso ao quadro da representação política-institucional. Para melhor entendimento, o quadro profissional foi organizado com base na seguinte distribuição: Carreiras Jurídicas (advogado, juiz, promotor de justiça, desembargador e procurador de justiça), Atividades Rurais (pecuarista, fazendeiro, agropecuarista, agricultor e proprietário rural), Professores, Profissionais da Saúde, Funcionários Públicos, Industrial, Comerciário e Bancário, Militares, Imprensa (Jornalista e comunicólogo em televisão) e Outros (engloba as profissões que são apresentadas com menor frequência: engenheiro civil, engenheiro agrônomo, economista, empresário, contador, administrador e técnico em contabilidade). 
Tabela 1: Carreira Profissional

\begin{tabular}{|c|c|}
\hline CARREIRA PROFISSIONAL & \% \\
\hline Carreiras Jurídicas & $25,2 \%$ \\
\hline Atividades Rurais & $16 \%$ \\
\hline Professores & $14 \%$ \\
\hline Profissionais da Saúde & $11,9 \%$ \\
\hline Funcionários Públicos & $6,3 \%$ \\
\hline Industrial, Comerciário e Bancário & $6,3 \%$ \\
\cline { 2 - 2 } Imprensa & $5,6 \%$ \\
\hline Militares & $1,4 \%$ \\
\hline Outros & $13,3 \%$ \\
\hline
\end{tabular}

Fonte: Dados organizados pelos autores.

A representação baiana durante o regime militar tem em seu quadro de carreira profissional a preponderância das profissões provenientes da área jurídica, com 25,2\%. Na sequência, as atividades rurais que apresentam índice de 16\%, enquanto professores e profissionais da saúde representaram 14\% e 11,9\% respectivamente. Em consonância com as categorias apresentadas por CODATO, COSTA E MASSIMO (2014), verifica-se a proeminência de ocupações profissionais de alto reconhecimento social, a exemplo dos profissionais da saúde, que aqui foram, por sua vez, majoritariamente constituídos por médicos (com exceção de dois cirurgiões-dentistas). Este perfil também evidencia para as carreiras flexíveis e outras com maior autonomia profissional, a exemplo das carreiras jurídicas e dos que exercem as atividades rurais.

Além de profissionais das áreas jurídicas e médicas, cabe frisar aqui as citações às áreas de educação, de serviços públicos e de comunicação. É possível constatar que a citação à categoria "professor", com predominância de vínculo com as universidades, indica o "pertencimento" à elite acadêmica, propiciando certa condição intelectual à atividade política. Por fim, a presença média de funcionários públicos e de jornalistas/imprensa indica tanto a proximidade quanto a expertise em torno dos "negócios públicos", fomentando o capital político necessário para a entrada na esfera política.

\subsection{Perfil político-partidário: o apoio ao regime}

A artificial estrutura democrática simbolizada pelo bipartidarismo adquiriu na Bahia conotações contundentes em prol da ARENA. O período pesquisado indica esta supremacia tanto pelo prisma da Câmara dos Deputados, como veremos adiante, como pelo controle do poder executivo, já que todos os governadores "escolhidos" pela Assembleia Legislativa da Bahia eram vinculados ao partido da situação, braço político do regime militar. Por seu lado o 
MDB (Movimento Democrático Brasileiro), além de representar isoladamente o estatuto legal oposicionista, foi obrigado a conviver com divergências internas durante o período. Para Jacobina (2010), o MDB baiano pode ser dividido em "autênticos-ortodoxos" e "adesistasmoderados":

No MDB havia o grupo "autêntico" que expunha uma crítica contundente ao regime e ao governo de ACM 1971-1975 e o MDB "adesista" que era contrário a essas críticas, especialmente a ACM [...] Membros do MDB autêntico baiano, de fato fizeram oposição, enquanto o MDB adesista fez acordos com a Arena e em alguns casos, como nas eleições parlamentares de 1974, essa facção impediu que os membros que representavam maior oposição tivessem espaço na mídia. (JACOBINA, 2010, p.40).

A fragilidade oposicionista contribuiu com o fortalecimento do partido governista, que cresceu apoiado no personalismo das figuras políticas locais que possuíam forte inserção entre as elites políticas nacionais. Por consequência, evidencia-se a concentração da representação política em alguns grupos de interesse e a consequente "personificação" em determinados líderes. Esse fenômeno pode ser constatado, como aponta Dantas Neto (2003), na atuação de Antônio Carlos Magalhães, protagonista do grupo político denominado pela literatura especializada como carlismo.

De 1967 a 1974 o carlismo afirmou-se como a principal força da ARENA na Bahia, embora se mantivesse, ainda, como grupo político apenas estadual. A Prefeitura de Salvador (1967-1970) serviu de vitrine administrativa e trampolim político e o esforço prosseguiu durante o primeiro mandato de governador de ACM (1971-1975), quando, ao tempo em que mantinha a sociedade civil baiana sob forte constrição autoritária, investia contra bases político-eleitorais de grupos conservadores rivais, no intuito, em parte consumado, de neutralizá-los, ou pulverizá-los. (DANTAS NETO, 2003, p.223).

Em linhas gerais, a estrutura partidária da ARENA, que incorporava grupos específicos de interesse local com forte ascensão no estado, atrelada à dinâmica repressora inerente ao regime militar, consolidou a representação política situacionista, tanto no âmbito do executivo, com a escolha indireta do governador pela Assembleia Legislativa, quanto do legislativo, como demonstra o gráfico abaixo: 
Gráfico 3: Representação por bancada partidária

ARENA $\square$ MDB

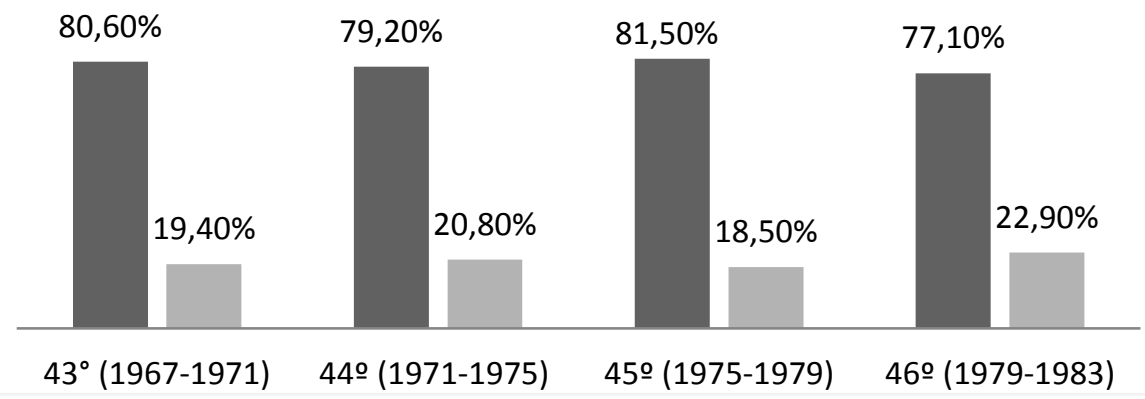

Fonte: Dados organizados pelos autores.

Os dados relativos à representação no legislativo demonstram a predominância de políticos vinculados à ARENA durante todo o período pesquisado. Na 43 ${ }^{\mathrm{a}}$ Legislatura (1967 a 1971), a representação da bancada baiana foi formada por 80,6\% de representantes da ARENA, ante 19,4\% do MDB. Na $44^{\text {a }}$ legislatura o MDB apresenta um crescimento de 1,4\%, chegando a 20,8\%; porém, a ARENA mantém a supremacia, alcançando 79,2\% de representantes.

Durante os anos de 1975 a 1979, que correspondem à 45 legislatura, a ARENA retoma o crescimento, alcançando $80,5 \%$ das cadeiras, contra 18,5\% do MDB. Vale ressaltar que este constitui o menor índice de representação apresentado pelo MDB baiano na câmara federal durante o regime militar. Todavia, já no bojo dos movimentos de abertura política, o MDB consegue ampliar sua participação, mesmo que de maneira tímida: na $46^{a}$ legislatura alcança $22,9 \%$ das vagas, contra $77,1 \%$ da ARENA.

Em suma, como já frisado, a ARENA assegura, durante o regime militar, a sua preponderância no que se refere à representação política da Bahia na Câmara dos Deputados. Tal constatação se evidencia na análise do período de forma integrada, onde se constata que a ARENA compôs 79,5\% da representação, ante 20,5\% do MDB.

O arranjo político destaca a bem sucedida organização da ARENA no território baiano. De acordo com Madeira (2002), a ARENA baiana foi constituída principalmente pelos políticos que advieram da antiga União Democrática Nacional (UDN) e do Partido Republicano (PR). Estes atores políticos já dispunham de forte influência devido à trajetória percorrida tanto na política estadual quanto nacional, resultando em considerável coesão partidária que contribuiu para um alto grau de estabilidade política na cena federal. 
Verificou-se que a ARENA baiana, além de possuir bancadas federais formadas basicamente por parlamentares experientes, com trajetórias prévias relativamente longas e com vinculações diretas aos partidos políticos existentes na fase multipartidária anterior ao período analisado, possui uma dinâmica pelo predomínio de suas principais lideranças. Esta análise identificou a presença de cinco lideranças de primeiro plano, encabeçando as principais alas do partido no Estado [Antônio Carlos Magalhães, Roberto Santos, Lomanto Júnior, Luís Viana Filho/Neto e Juraci/Jutaí Magalhães]. (MADEIRA, 2002, p. 45).

Em contrapartida, o MDB baiano era composto pela maioria do Partido Trabalhista Brasileiro (PTB) e pelo Partido Social Democrata (PSD). Esta composição proporcionou a gestação de grupos internos que, em linhas gerais, apontavam posições distintas em relação ao regime militar. Nesse sentido é possível afirmar, ainda, que os "autênticos" sucumbiram às articulações governistas encampadas pelos "adesistas", o que influenciou os resultados eleitorais e contribuiu para o fortalecimento da ARENA. O exponencial crescimento do MDB em nível nacional no pleito de 1974 é prova inconteste desta realidade, onde se constata que, para a Câmara dos Deputados, sua votação passou de 28\% para 44\% (BENEVIDES, 1986). Enquanto isso, como apontado anteriormente, a votação média do MDB na Bahia foi de 20,5\%, tendo seu pior desempenho exatamente no pleito de 1974, registrando 18,5\%. Em suma, o avanço nacional da oposição representado pelo MDB não respingou na Bahia.

As relações estabelecidas neste cenário apontam para o apoio dos parlamentares baianos aos governos militares. Tal apoio, como destaca Dias (2016), remonta ao período anterior ao golpe de 1964, com a montagem da coalizão que elegeu Lomanto Júnior para Governador em 1962 e com participação nas conspirações para a instauração do regime militar no país:

O círculo se fechou no congresso com a participação ativa de deputados baianos, entre eles, Antônio Carlos Magalhães que além de haver negociado nos bastidores a candidatura de Castelo Branco foi o principal disseminador da tática sorbonista de criar um clima psicológico tenso que favorecesse a queda de Goulart. Entre maio de 1963 e março de 1964, dos 23 pronunciamentos feitos pelo deputado federal Antônio Carlos Magalhães, 15 se referiam ao presidente João Goulart ou a seus auxiliares próximos com a clara intenção de desgastar a imagem do governante e promover a sua desestabilização política. (DIAS, 2016, p. 35).

Por fim, o cenário partidário em questão nos remete a duas importantes conclusões. Em primeiro lugar, verifica-se, a partir dos dados apresentados, que em nenhuma legislatura pesquisada a supremacia da ARENA foi ameaçada, mesmo no período de relativa ascensão do MDB em nível nacional. E, como consequência disso, em segundo lugar constata-se a significativa adesão institucional da representação baiana ao regime imposto. Para além das vinculações partidárias, esta adesão reside na própria essência excludente e elitista da representação, uma vez que, mesmo compondo a oposição autorizada ao governo, o MDB, majoritariamente "adesista", recrutou seus representantes na fonte de privilegiados da sociedade 
baiana. Esses elementos congregados contribuíram para diminuir o "peso" do parlamento como instrumento de luta e resistência contra a ditadura militar.

\section{Considerações finais}

A noção de que a formação política do Estado brasileiro foi composta pelas elites dirigentes de cada época (CARVALHO, 2003) e que se configurou no processo de circulação e reprodução desses grupos adquire veracidade na análise da representação baiana na câmara federal durante o regime militar. A elitização da representação funcionou em todos os aspectos no caso da Bahia.

O principal motivo para o êxito do processo se deve à estratégia da classe dirigente militar de adequar preceitos democráticos liberais à centralização decisória, que criou situação paradoxal no âmbito da organização política nacional. A partir do golpe de 1964 impôs-se à sociedade uma possibilidade limitada em torno da escolha da representação política: sufrágio apenas para o poder legislativo num contexto de concorrência limitada a dois partidos políticos, um da ordem e outro da oposição. Como estratégia de controle, a limitação à participação visava, naturalmente, a limitação de acesso da oposição aos canais decisórios, visto que os cargos dirigentes do poder executivo em âmbito nacional e regional já estavam cerceados.

O trabalho procurou demonstrar o estabelecimento desse perfil elitista a partir da investigação de quatro variáveis. Pode-se constatar que a representação política da Bahia na Câmara dos Deputados durante o regime militar esteve organizada de acordo com os traços que apontam para o reordenamento das elites locais à esfera política, logo, as características sociopolíticas dos deputados baianos apontam para um perfil composto majoritariamente por parlamentares do sexo masculino, com alto grau de escolaridade, que apresenta ocupações profissionais com maior disposição ao acesso à esfera pública e grande reconhecimento social. No âmbito partidário, constata-se a ascendência do partido da ordem sobre a oposição, mesmo nos pleitos em que o MDB conseguiu ampliar sua participação eleitoral em nível nacional, o que configura a adesão incondicional do legislativo federal ao regime militar.

Cabe destacar que os movimentos ordenados pelas elites se encontram evidentes nas entrelinhas das relações do sistema político-eleitoral que, por sua vez, também é percebido no conjunto que permeia a composição da representação política da Bahia. Por conseguinte, para Simoni Júnior, Dardaque \& Mingardi (2016), quanto mais semelhante o corpo político em relação aos representados em suas clivagens sociais, menor seria a distância dos interesses entre esses conjuntos de atores e, portanto, maior chance de se tratar de temas que realmente fossem de interesse público.

O perfil representativo institucional resultante do processo de análise destoa da realidade social do estado no período, que se caracteriza, sobretudo, pelo baixo nível de 
formação educacional superior e por maior equilíbrio demográfico entre homens e mulheres (Brasil, 2020). Este panorama de conflito entre os índices sociais e os dados evidenciados no perfil da representação baiana resulta, no entendimento aqui proposto, da imposição de uma agenda restritiva de competição proporcionada pela legislação eleitoral vigente. $O$ distanciamento entre representantes e representados expõe as contradições de um modelo representativo esquizofrênico, criado para camuflar os verdadeiros interesses do sistema: o controle autoritário das instituições políticas por grupos dirigentes oriundos das elites militares e civis.

\section{Referências}

BENEVIDES, Maria Victória. Ai que saudade do MDB. Lua Nova, v.3, n1, Junho, p. 51-67, 1986. Disponível em: http://dx.doi.org/10.1590/S0102-64451986000200006. Acesso em: 15 out. 2019.

BRASIL. Estatística da educação básica no Brasil. Extraído do Relatório para a Conferência Internacional de Educação em Genebra, (1996). Disponível em: http://portal.inep.gov.br/documents/186968/484154/Estat\%C3\%ADsticas+da+educa\%C 3\%A7\%C3\%A3o+b\%C3\%A1sica+no+Brasil/e2826e0e-9884-423c-a2e4658640ddff90?version=1.1. Acesso em: 6 jan. 2020.

CARVALHO, José Murilo de. A construção da ordem: a elite política imperial: teatro de sombras: a política imperial. 2. ed. Rio de Janeiro: Civilização Brasileira, 2003.

CODATO, Adriano Nervo; COSTA, Luiz Domingos; MASSIMO, Lucas. Classificando ocupações prévias à entrada na política: uma discussão metodológica e um teste empírico. Opinião Pública, Campinas, v. 20, n. 3, p. 38-49, dez. 2014.

DAHL, Robert A. Poliarquia: participação e oposição. São Paulo: Editora da Universidade de São Paulo, 2005.

DANTAS NETO, Paulo Fábio. Quebra da casca do ovo: a elite baiana e a obra do golpe de 1964. 2004. Disponível em: http://www.fundaj.gov.br/observa_bahia_01.pdf. Acesso em: 22 jul. 2018.

DANTAS NETO, Paulo Fábio. Surf nas ondas do tempo: do carlismo histórico ao carlismo pós- carlista. Cadernos do CRH (UFBA), Salvador, v. 39, n. 101, p. 213-255, 2003.

DIAS, José Alves. Rumo ao palácio: as estratégias de dominação do espaço político na Bahia durante a ditadura. Vitória da Conquista: Editora da UESB, 2016.

FIGUEIREDO FILHO, R.M. Educação escolar brasileira e o mundo de OZ. Rev. Pedagogia em ação, v. 2, n. 2, p. 1-117, 2010. 
HARTLYN, Jonathan. A democracia na América Latina após 1930. In: BETHELL, L. (org). História da América Latina: a América Latina após 1930. São Paulo: EDUSP, 2009. p. 127196.

INSTITUTO BRASILEIRO DE GEOGRAFIA E ESTATÍSTICA. Censo demográfico-2010. Disponível em: https://ww2.ibge.gov.br/home/estatistica/populacao/censo2000/default.shtm. Acesso em: 29 jun. 2019.

INSTITUTO BRASILEIRO DE GEOGRAFIA E ESTATÍSTICA. População Residente Bahia. População residente por microrregião segundo sexo - período: 1980. Dados do Instituto Brasileiro de Geografia e Estatística - IBGE. Disponível em: http://tabnet.datasus.gov.br/cgi/tabcgi.exe?ibge/cnv/popba.def. Acesso em: 25 mar. 2020.

JACOBINA, André Teixeira. Clivagens Partidárias: ARENA E MDB baianos em tempos de distensão (1974-1979). 2010. Dissertação (Mestrado em História) - Faculdade de Filosofia e Ciências Humanas, Universidade Federal da Bahia, 2010.

MADEIRA, Rafael Machado. ARENA ou ARENAs? A coesão partidária da legenda do regime em três estados brasileiros. 2002. Dissertação (Mestrado em Ciência Política) Instituto de Filosofia e Ciências Humanas, Universidade Federal do Rio Grande do Sul, 2002.

MICHELS, Robert. Sociologia dos Partidos Políticos. Brasília: Editora da Universidade de Brasília, 1982.

MOSCA, G. A. Teoria da Classe Política Dirigente. In MOSCA G e BOUTHOUL, G. História das Doutrinas Políticas. $3^{\text {a }}$ Edicação. Rio de Janeiro: Zahar, 1968, p.71-87.

MUCINHATO, Rafael; Moreira Dardaque. Quem são os deputados Brasileiros? Um balanço do perfil biográfico de 1986 a 2012. In:MOISÉS, José Álvaro. O Congresso Nacional, os partidos políticos e o sistema de integridade: representação, participação e controle interinstitucional no Brasil contemporâneo. Rio de Janeiro: Konrad Adenauer Stiftung, 2014, p. 72-91.

NAPOLITANO, Marcos. 1964: História do Regime Militar Brasileiro. São Paulo: Contexto, 2014.

NORRIS, Pippa. Recrutamento Político. Revista de Sociologia e Política. Curitiba, v. 21, n. 46, p. 11 32, 2013. Disponível em: http://dx.doi.org/10.1590/S0104-44782013000200002. Acesso em: 5 set. 2019.

ORTEGA Y GASSET, José. A Rebelião das Massas. Rio de Janeiro: Livro Ibero-Americano, 1959.

PARETO, V. Tratado de Sociologia Geral. In: RODRIGUES, J. (org). Pareto: Sociologia. São Paulo: Ática, 1984, p. 52-61. 
RODRIGUES, Leôncio Martins. Mudanças na classe política brasileira. São Paulo: Publifolha, 2009.

SCHUMPETER, Josep A. Capitalismo, Socialismo e Democracia. Rio de Janeiro: Zahar Editores. 1984.

SIMONI JUNIOR, S.; MUCINHATO, R. M. D.; MINGARDI, L. A elite parlamentar brasileira de 1995 a 2010: até que ponto vai a popularização da classe política? Colombia Internacional, Bogotá, v. 87, p. 109-143, 2016.

SIMÕES, Teotonio. Os Bacharéis na Política: a política dos bacharéis. 2006. Tese (Doutorado em Ciência Política) - Departamento de Ciência Política, Universidade de São Paulo, 2006.

SOUZA, D. M. R.; OLIVEIRA, M. C. S.; MAGALHÃES, L. D. R. A educação baiana em tempos de ditadura: notas deu um primeiro levantamento documental. In: SEMINÁRIO NACIONAL DE ESTUDO E PESQUISA EM EDUCAÇÃO NO CAMPO, 3., São Paulo. Anais [...]. São Paulo: Ed. UFSCAR, 2015.

Artigo submetido em: 2020-01-10

Reapresentado em: 2020-04-11

Aceito em: 2020-04-28 